\title{
SABER HABLAR VS. SABER INTERPRETAR: SOBRE EL CONCEPTO DE CONGRUENCIA EN E. COSERIU
}

\author{
ROSARIO GONZÁLEZ PÉREZ \\ Universidad Autónoma de Madrid
}

\section{INTRODUCCIÓN}

La avalancha de estudios sobre el discurso y el texto en los últimos treinta años podría hacer pensar que se dan ya las condiciones, dentro del ámbito lingüístico, para acometer una gramática supraoracional con perspectivas de éxito. Sin embargo, la sensación de dispersión que se tiene al enfrentar la abrumadora cantidad de bibliografía al respecto no deja de producir una cierta zozobra. Por lo que atañe al dominio del español, existen dos caminos más o menos diferenciados por los que han discurrido los trabajos a que me he referido más arriba: por un lado el camino de la construcción textual, que incluye el estudio del texto como unidad - naturaleza y delimitación-, de las partes que lo componen, de los elementos que lo forman, de las propiedades que lo caracterizan, de las condiciones que regulan su producción y de los patrones-tipo textuales del español. Por otro, el camino de las relaciones entre lo dicho y el contexto en que se dice, que incluye el estudio de las condiciones de emisión de los mensajes, de las normas que regulan la comunicación y, por tanto, también de las interacciones verbales a que aquélla da lugar; incluye también el análisis de los tipos de actos de habla así generados o el estudio de la influencia del saber cultural y la experiencia acumulada en la comunicación. Estos dos caminos se cruzan en numerosas ocasiones, por ejemplo cuando se trata el discurso oral o, dentro del estudio de las propiedades textuales, cuando se estudia la propiedad de la coherencia; y no resulta raro que el mismo fenómeno aparezca en unos autores con un tratamiento textual (Reinhardt 1980 y Giora 1985, en su concepción de la coherencia) o con un tratamiento pragmático (Comte 1988 o Charolles 1994, también para la propiedad de la coherencia). Asimismo, y probablemente porque no existe aún un estudio general de las características que regulan la producción de textos en español o una pragmática específica para el español ${ }^{1}$, encontramos una gran desigualdad en

\footnotetext{
${ }^{1}$ Muchas veces lo que nos encontramos son aplicaciones al español de marcos teóricos muy generales, con ejemplos previamente seleccionados, con lo que siempre queda la duda del grado de aplicabilidad a corpora mayores en nuestra lengua. Para Á. López García $(2000,7)$

La gramática española de los últimos treinta años se caracteriza por la irrupción de planteamientos teóricos, hasta el punto de que ya resulta difícil trabajar en dicho campo sin asumir más o menos
} 
el interés que han suscitado diversos aspectos de los estudios pragmático-textuales: mientras que no hay prácticamente conector del español que no haya sido objeto de varios trabajos o conjunción o adverbio oracional que no haya sido reinterpretado a la luz del discurso $^{2}$, otros fenómenos, como la coherencia o el papel del oyente en la recepción del mensaje $^{3}$ han resultado menos atractivos para los investigadores.

En este panorama de luces y sombras, desigual, pero muy interesante, la figura del profesor Eugenio Coseriu aporta una visión integral y abarcadora de los fenómenos que tienen que ver con el hablar en general y con la lengua en particular ${ }^{4}$. La intención de Coseriu de construir una teoría que dé cuenta de la actividad del hablar en general y de cómo se articula ésta en distintos niveles es el núcleo que sustenta el pensamiento gramatical del maestro rumano.

\section{HACIA UNA TEORÍA DEL SABER ELOCUCIONAL}

A entender esta concepción integral e integradora de todos los fenómenos que afectan al lenguaje ayuda un somero vistazo a la formación del lingüista rumano, que incluye, además de sólidos conocimientos filológicos, amplísimos conocimientos de distintas lenguas modernas (románicas, germánicas, eslavas y de otras ramas) tanto en su estado actual como en su devenir histórico, junto a profundos conocimientos también de lenguas clásicas y de latín vulgar. Todo ello hace que Coseriu pueda tener el privilegio de una visión panorámica y desde arriba de los hechos lingüísticos, a los que, sin duda alguna, su espléndida formación lingüístico-filológica, dota de un sentido global difícilmente explicable de otro modo. Por ello, la actividad académica e investigadora del sabio rumano-que podemos comprobar en su abrumadora bibliografía ${ }^{5}$ - transita por una vastedad de caminos verdade-

explícitamente los presupuestos metodológicos de una determinada escuela lingüística [...]. Después de la segunda guerra mundial se han venido sucediendo distintos modelos teóricos que se reclamaban exclusivos y que tendían a constituir una red internacional del saber por encima de las lenguas investigadas.

Un valioso instrumento para conseguir esa esperada pragmática del español lo constituyen los corpora de referencia como el de Antonio Briz en el grupo Val. Es. Co., a partir del que se pueden deducir los rasgos del español, comparar con distintas lenguas y situar adecuadamente el español en un marco general.

${ }^{2}$ Esta afirmación es válida, sobre todo, en lo que se refiere a estudios sincrónicos. Por lo que respecta a estudios históricos de diversos nexos desde la perspectiva discursiva, su interés es relativamente reciente. Al estudio del discurso desde la perspectiva histórica han dedicado trabajos los profesores J. J. de Bustos Tovar, R. Cano, J. L. Girón Alconchel, F. J. Herrero Ruiz de Loizaga o S. Iglesias Recuero.

${ }^{3}$ Muy estudiado en el ámbito literario lo que ha dado lugar a la estética de la recepción, pero prácticamente sin referencias al papel del receptor en la comunicación en el terreno de la Lingüística.

${ }^{4}$ Creo, con José Polo $(2000,615)$, que en el ámbito del español no se ha puesto de relieve con suficiente énfasis la importante vocación integradora del pensamiento gramatical de Coseriu. Y aunque contemos con aplicaciones globales de los presupuestos coserianos en semántica, sobre todo, y menos, aunque también, en sintaxis (el profesor Polo alude en el trabajo citado más arriba a la Sintaxis funcional básica del español, de Manuel Martín Cid, publicada por la Universidad de Sevilla en 1998), en lo que afecta al análisis del discurso se deja notar esta falta de aplicación.

5 La bibliografía de E. Coseriu puede consultarse ordenada cronológicamente en la siguiente página web: http:// www.coseriu.de. Esta web se inserta dentro de un proyecto -en el que colaboran la profesora Brigitte Schlieben-Lange y los doctores Johannes Kabatek y Reinhardt Meisterfeld- encaminado a la edición de los materiales completos de la obra coseriana. Para el ámbito del español, los doctores Benjamín García Hernández y José Polo se han ocupado de inventariar, ordenar y clasificar diversos materiales del archivo

Odisea, $n^{\circ} 3,2003$ 
ramente poco habitual, que los profesores Benjamín García Hernández y José Polo (1999, 25 26) han resumido de este modo:

Coseriu ha tratado de abarcar y de cultivar, en muchos casos con la colaboración de sus discípulos, casi todos los dominios atinentes al lenguaje; así, la filosofía del lenguaje, la teoría del lenguaje y de la lingüística, la fonología, la teoría gramatical, la semántica léxica, la lingüística del hablar y la lingüística del texto, la dialectología, la sociolingüística y la estilística de la lengua; el metalenguaje y el discurso repetido; la teoría de la historia lingüística; la gramática histórica y la historia de lenguas; la lingüística «aplicada» (traducción, corrección idiomática, enseñanza de lenguas, política lingüística); la historia de la filosofía del lenguaje y de la lingüística.

También por esta razón, en los trabajos de Coseriu se repite insistentemente una concepción del lenguaje articulada en niveles que tiene como base la actividad lingüística del hablar y que supone una inversión del punto de partida saussureano en la investigación lingüística: no es la lengua el centro de interés de la lingüística o, al menos, no la lengua como un ente real desligado del habla, del hablar, sino que la lengua incluye el habla y la perspectiva desde la lengua ha de integrar necesariamente el habla. Estas ideas, tempranamente expuestas por Coseriu, revelan el antidogmatismo de este lingüista, al que injustamente se le ha achacado desde determinadas posturas teóricas una rigidez inmanentista en sus planteamientos que choca con la lectura directa de sus obras. Por poner un ejemplo, en un conocido artículo suyo «Determinación y entorno. Dos problemas de una lingüística del hablar», publicado por primera vez hace casi 50 años (1955-1956), se expresa así su autor $(1962 \mathrm{a}, 282-283)^{6}$ :

La verdad es que resulta difícil constituir la ciencia de aquello que queda cuando del hablar se aísla la «lengua», pues lo que queda son hechos particulares y heterogéneos. Y más difícil aún es fundar la lingüística de la parole si se acepta la distinción de F. de Saussure como una distinción «real». La lengua, en realidad, integra el habla; y la distinción entre langue y parole, además de admitir varias interpretaciones, no es «real», sino «formal» y metodológica.

La modernidad de las tesis de Coseriu, que plantean decididamente el estudio de la variedad dentro de lo sistemático, no le impiden preguntarse por las limitaciones de una lingüística del habla (1962a, 285):

De todos modos, parece indudable que hay que reconocer la necesidad de una cierta lingüística de la parole. [...] Pero, admitida dicha necesidad, hay que ver si deben admitirse

\footnotetext{
del profesor Coseriu. En relación con ello, el profesor Polo ha publicado ya diversos textos inéditos del lingüista rumano en la revista Analecta Malacitana.

${ }^{6}$ También en otros trabajos publicados en la década de los cincuenta observamos esa concepción del lenguaje y de la lingüística. En «Sistema, norma y habla» (1962b, 15) afirma Coseriu que «También es verdad que la realidad del lenguaje es movimiento (es decir, que el lenguaje es actividad, es «perpetua creación») y que, por lo tanto, todo sistema sincrónico se basa en un equilibrio inestable, es necesariamente una abstracción.»
}

Odisea, $\mathrm{n}^{\circ} 3,2003$ 
también sus limitaciones. Cabe preguntarse si una lingüistica del hablar debe realmente justificarse desde el punto de vista de la lengua y dentro del esquema saussureano. Obsérvese que la lingüística del hablar se considera como otra lingüística y se señala como «necesaria» (aún no constituida) sólo porque se acepta la distinción saussureana y porque, implícitamente, se admite que la lingüística es ciencia de la «lengua». Pero, desde otro punto de vista, cabría más bien preguntarse si hay una lingüística que no sea lingüística del hablar. La «lengua» misma, ¿qué otra cosa es si no un aspecto del hablar?

Ni tampoco le impiden concluir algo que en la actualidad solemos plantear como novedoso (1962a, 285), esto es que «el objeto de la lingüística («ciencia del lenguaje») sólo puede ser el lenguaje, en todos sus aspectos. Y el lenguaje se da concretamente como actividad, o sea, como hablar [...]». Por ello «Determinación y entorno» - como gran parte de la producción coseriana - constituye, en realidad, una descripción sintética de una lingüística del hablar, del saber hablar, y un intento también de una precoz lingüística del texto ${ }^{7}$.

La concepción coseriana del lenguaje como una actividad humana universal que se realiza de forma individual en una lengua (Coseriu 1973, 269) tiene importantes consecuencias a la hora de abordar el estudio lingüístico: por un lado, el lenguaje nunca es actividad colectiva (el hablante pone en práctica la facultad del lenguaje solo. Aun cuando se hable en un grupo habrá turnos de palabra, en principio individuales; incluso si se habla a la vez, cada parlamento no pierde su individualidad) y por otro, es una actividad individual históricamente determinada, es decir, el hablar individual se realiza de acuerdo a una lengua, se presenta como una lengua, que funciona como una técnica para poder realizar el acto individual de habla. Como señala Coseriu $(1973,269)$ «no hay hablar que no sea hablar una lengua». Lo colectivo no es, pues, el hablar concreto, sino la técnica histórica, la lengua, que nos permite actualizar cada acto individual de habla. Teniendo en cuenta lo expuesto, en el lenguaje se pueden distinguir tres niveles: uno universal, otro histórico y otro individual, determinados los tres por el punto de vista adoptado en el estudio del lenguaje y de sus manifestaciones lingüísticas. Cada uno de estos niveles o puntos de vista se corresponde con el desarrollo de una actividad diferente, constituye un tipo de saber distinto y tiene como resultado un producto específico, como muestra el siguiente cuadro (Coseriu 1973, $273 ; 1977,242 ; 1981,14$ o 1988, 92):

\begin{tabular}{|l|l|l|l|}
\hline \multicolumn{1}{|c|}{ NIVEL } & \multicolumn{1}{c|}{ ACTIVIDAD } & \multicolumn{1}{c|}{ SABER } & \multicolumn{1}{c|}{ PRODUCTO } \\
\hline Universal & Hablar en general & Saber elocucional & Totalidad de lo «hablado» \\
\hline Histórico & Lengua concreta & Saber idiomático & Lengua abstracta \\
\hline Individual & Discurso & Saber expresivo & «Texto» \\
\hline
\end{tabular}

Es evidente, por razones tanto científicas como metodológicas, que ha sido y es -a pesar de que encontremos a menudo opiniones en sentido contrario- el nivel histórico el objeto de atención preferente por parte de los lingüistas, antiguos y modernos. Ello ha llevado a desarrollar una lingüística de las lenguas (Coseriu 1973, 275) en la que el interés

\footnotetext{
7 Antonio Narbona $(1989,150)$ señala como nuevo camino lingüístico posterior al estructuralismo la lingüística del texto, y en el mismo sentido que Coseriu indica que «la superación de la idea saussureana de langue ha obligado a no ceñirse a una lingüística de los enunciados y a incluir también la enunciación.»
}

Odisea, $\mathrm{n}^{\circ} 3,2003$ 
de los lingüistas se centra, sobre todo, en el saber idiomático, es decir, en la técnica lingüística determinada históricamente que se realiza en una lengua concreta. Pero, incluso para entender bien el funcionamiento de esa técnica lingüística en que se basa el saber idiomático, los otros dos niveles tienen también su importancia. Y también deben ser considerados, de tal manera que «junto a la lingüística de las lenguas, hay sitio para una lingüística del hablar y para una lingüística del discurso (o del texto), igualmente necesarias para una comprensión efectiva del lenguaje [...]»(Coseriu 1973, 275).

La relación entre los tres niveles anteriores, bien que necesaria, resulta difícil de precisar. Aunque el propio Coseriu señala, como he expuesto anteriormente, que hay sitio en las investigaciones sobre el lenguaje para una lingüística equivalente a cada nivel, las dificultades para acometer una lingüística del discurso y, sobre todo, del hablar son grandes. Y ello no sólo porque el grado de desarrollo de estas dos lingüísticas sea menor — la lingüística de las lenguas lleva siglos de rodaje- , sino porque la accesibilidad al objeto de estudio es clara en la lingüística de las lenguas, no lo es tanto en la lingüística del discurso y es bastante difusa en la lingüística del hablar en general. Si la lingüística del discurso, que vive en la actualidad un espectacular desarrollo, es aún una lingüística que se está fundamentando teóricamente — tal vez esto sea así con todos los tipos de lingüística, por más ilusiones que nos hagamos los lingüistas respecto a los marcos teóricos con los que trabajamos-, la lingüística del hablar en general, aún se encuentra a la búsqueda de su objeto y de los fundamentos que la sustenten, ya que delimitar con precisión el objeto del saber elocucional es una tarea muy compleja, pues estamos hablando de un saber universal que puede adoptar formas diferentes al realizarse históricamente en una lengua, y que como tal saber universal puede sobrepasar el ámbito de lo puramente lingüístico ${ }^{8}$. En efecto, aunque el propio Coseriu reconoce que el hablar se produce fundamentalmente sobre la base de las lenguas, reconoce también que el saber elocutivo no consiste sólo en saber idiomático (sobre las lenguas). No basta para saber hablar con aplicar con corrección lo que sabemos de una lengua, sino que el hablar en general tiene que ver también con lo lógico — con los principios generales que regulan la actividad de pensar y, por tanto, la de hablar como manifestación del pensamiento- y con lo experiencial - con las opiniones y creencias acerca de las cosas - En cuanto a lo lógico como fundamento del hablar Coseriu lo ilustra de esta manera $(1977,242)$ :

Así, por ejemplo, en un «razonamiento» como: Los franceses son numerosos —Pedro es francés-Por consiguiente, Pedro es numeroso, esto último resulta, sin duda, «inadmisi-

\footnotetext{
${ }^{8}$ La mayoría de los lingüistas admiten sin reservas, como no puede ser de otro modo, las lingüística de las lenguas y la del discurso, pero rechazan o, al menos, excluyen la posibilidad real y efectiva de una lingüística completa del saber elocucional. La falta de una visión integradora de los tres saberes - elocucional, idiomático y expresivo - no sólo se debe, aunque en gran parte sí, a un grado de dificultad diferente para abarcar el objeto que describiría cada una de las lingüísticas que corresponden a estos saberes, sino también a la formación científica de los lingüistas y a la concepción más o menos restringida de la gramática y de la lengua que se tenga. En cuanto a la lingüística del discurso, vemos cómo en España, y a pesar de la ingente cantidad de estudios dentro de esa línea que hay en los últimos veinte años, no se ha superado un cierto reduccionismo que recuerda al atomismo de los estudios gramaticales. Contamos con trabajos pormenorizados sobre conectores, particularidades que afectan a la tipología textual, fórmulas que articulan de distintas maneras los discursos, pero son mucho menos frecuentes estudios con una pretensión de generalidad que sirvan de fundamento a una gramática supraoracional, todavía por hacer.
}

Odisea, $n^{\circ} 3,2003$ 
ble», pero no desde el punto de vista de la lengua española como tal [...], sino desde el punto de vista del hablar en general, precisamente, porque esa expresión es lógicamente contradictoria (ya que equivale a afirmar que «un francés es muchos franceses»).

Y en cuanto a lo experiencial como base del saber elocucional señala Coseriu (1977, 243):

Análogamente, expresiones como «el sol», «la luna», aun no tratándose de nombres propios, valen como designaciones individuales sobre la base del «conocimiento general del mundo"; y en muchas comunidades (que, sin embargo no coinciden con las comunidades lingüísticas), expresiones como tonto como un burro - inteligente como un burro se interpretan como equivalentes sobre la base de las opiniones acerca de las «cosas» (o sea, en este caso, acerca de los burros).

Y esto es lo que lleva probablemente a afirmar al lingüista homenajeado que «El hablar es un plano autónomo del lenguaje, independiente de las lenguas» $(1977,243)$.

A los tres niveles del lenguaje corresponden también tipos de contenidos lingüísticos diferenciados (cfr. Coseriu 1997, 83-86): la designación o referencia a la realidad, a cosas o estados de cosas, en el nivel universal; el significado o contenido determinado por las oposiciones idiomáticas que funcionan en una lengua, en el nivel histórico y el sentido o contenido correspondiente a lo que se dice en una situación determinada, en el nivel individual. Y la valoración del hablar en estos tres niveles es distinta y autónoma en cada caso:

Así, la conformidad con el saber elocucional (exigencia de claridad, coherencia, nocontradicción, no-tautología, etc.) puede llamarse congruencia; la conformidad con el saber idiomático es la corrección (idiomática); y la conformidad con el saber expresivo es lo que se llama lo apropiado. (Coseriu 1981, 14).

Y es nuevamente en el plano correspondiente al hablar en general donde las normas que regulan el funcionamiento de esta actividad $-\mathrm{y}$ que permiten valorar o no como congruente lo dicho o lo interpretado - son peor conocidas y ello obedece a dos factores:

a) La confusión de las normas lógicas del saber elocucional con las reglas de una lengua particular.

b)La aplicación indiscriminada del método inductivo, por la cual, el hecho de encontrar una regla lógica en una lengua determinada y luego en algunas otras hace que se atribuya esta regla por extensión a todas las lenguas.

El principio de la congruencia regula, pues, el plano de la técnica universal del hablar ya que es la base que intuitivamente reconocemos los hablantes -los hablantes ingenuos, no los investigadores - en los procedimientos que usamos no sólo para hablar, sino también para interpretar lo que nos dicen otros. En efecto, la teoría lingüística de fondo que anima todo el pensamiento de Coseriu no es sólo una teoría del saber hablar, es decir, saber 
construir, en tres niveles diferentes (saber hablar en general, saber hablar en una lengua y saber hablar en una lengua y en una situación determinadas), sino que, implícitamente es también una teoría del saber interpretar. Y en el saber interpretar el principio de la congruencia es fundamental para valorar lo que se dice y aceptarlo o rechazarlo, pero también es fundamental para interpretar lo que aparentemente se nos presenta como incongruente. Cualquiera espera de los demás que hablen de manera que podamos interpretar lo que nos dicen. Por ello, cuando alguien emite un mensaje de contenido aparentemente incomprensible, no lo rechazamos sin más, sino que, al menos en un primer momento, intentamos dotarlo de congruencia. A esta forma de proceder la denomina Coseriu «norma de conducta de la tolerancia» $(1988,273-274)$ :

La norma de la congruencia se manifiesta también -indirectamente- en la norma de conducta de la tolerancia: el hablante espera que los otros hablen con sentido y congruentemente. Por eso, no rechaza sin más lo incongruente, sino que lo acepta al menos provisionalmente e intenta interpretarlo como algo que tiene sentido y es congruente. En el plano del hablar en general tenemos, por una parte, la norma de la congruencia y la norma de conducta de la tolerancia, y, por otra parte, tenemos un procedimiento de interpretación del hablar de otros, al que le son inherentes esas dos normas.

El procedimiento de la interpretación tolerante es un procedimiento del entender en el que confía el hablante nativo también en su hablar. Espera que se le interprete de una manera tolerante.

Aunque los principios de la congruencia y de la tolerancia interpretativa - este segundo incluido en el primero y dependiente de él— pertenecen al plano en que se sitúa el saber elocucional, tienen evidentes repercusiones en los planos del saber idiomático y del saber expresivo hasta el punto de que las lenguas particulares pueden anular incongruencias, es decir, normalizar expresiones o funciones lingüísticas en contradicción con los principios generales del pensamiento o con el conocimiento general del mundo y de las cosas; un ejemplo de ello lo constituirían los pleonasmos intensivos en español (Coseriu 1988, 140), sancionados por la tradición idiomática en una lengua particular — en este caso, el español—y que anulan la incongruencia de expresiones como

\section{Lo vi con mis ojos \\ Lo vi con mis propios ojos \\ Lo mató con sus propias manos,}

presentes desde etapas muy tempranas del idioma, como prueba este conocido ejemplo del Poema de Mio Cid:

De los sos ojos tan fuertemientre lorando.

Y en el nivel del saber expresivo, en el texto, el tipo de texto, la intención comunicativa y la situación expresiva pueden forzar la aceptación de mensajes aparentemente contradictorios con los principios que rigen el saber elocutivo e incluso pueden llevarnos a tolerar la 
incongruencia cuando sentimos que es intencionada, que obedece a un plan. Por eso aceptamos sin problemas producciones literarias o festivas del tipo de la siguiente octava real de Perito en lunas:

\section{XXIV}

Danzarinas en vértices cristianos

injertadas: bakeres más viüdas,

que danzan con los vientos, ya gitanos

de palmas y campanas, puntiagudas.

Negros, hacen los vientos gestos planos,

indices, si no agallas, de sus dudas,

pero siempre a los nortes y a los estes

danzarinas, si etíopes, celestes.

(Miguel Hernández 1933. «Danzarinas en vértices cristianos», ed. de Leopoldo de Luis y Jorge Urrutia. Obra poética completa. Madrid: Alianza Editorial, 1988, p. 56);

en este texto, Miguel Hernández describe unas veletas creando lo que Schmidt $(1980,160)$ denomina un comunicado estético polivalente, es decir, un tipo de mensaje en el que los signos usados, sin abandonar su codificación lingüística normalizada, generan una polivalencia semántica mediante diversos procedimientos -lingüísticos o poéticos - que obligan a los receptores a poner en funcionamiento estrategias comunicativas ya conocidas y a operar sobre ellas modificaciones, allí donde lo necesiten. El reconocimiento del poema de Miguel Hernández como un texto que obedece a un plan, es decir, que tiene una intención es lo que nos permite poner en funcionamiento el principio de la tolerancia interpretativa y evitar su rechazo. Es evidente que no podemos aplicar sin más lo que J. C. Moreno Cabrera denomina el principio de la automatización retroactiva, «que exige al hablante la emisión más rápida posible que sea interpretable» $(2002,30)$, sino que el receptor de este poema debe estar dispuesto a confiar en el emisor y a suplir la imposibilidad de automatismo interpretativo con otras estrategias que se basan en la acogida del texto del emisor, del que sabemos o intuimos que es aparentemente incongruente y debemos estar dispuestos, por tanto, a colaborar interpretativamente para descubrir la congruencia de lo que, en principio, no la tiene. En el texto del poeta alicantino, las características prototípicas del objeto cantado -por otro lado, un objeto que no constituye uno de los topoi poéticos tradicionales, lo que también dificulta la interpretación - vienen representadas por palabras que indican el movimiento y el color, pero también la localización de ese objeto (el sintagma en vértices cristianos / injertadas ...-vv. 1-2- alude sin duda al lugar donde están situadas las veletas, normalmente en la parte más alta del campanario de una iglesia). Las veletas, de color negro y movidas por el viento son presentadas como Danzarinas en vértices cristianos / injertadas, se dice de ellas que danzan con los vientos, que son danzarinas [...] celestes, en alusión a que señalan en los cielos la dirección del viento, por lo que se dice también que el viento las mueve a veces vacilando de un sitio a otro como si fueran un dedo que indica su dirección (los vientos son índices, si no agallas, de sus dudas, / pero siempre a los nortes y a los estes / danzarinas, [...], vv. 6-9). En cuanto al color, las veletas son bakeres más viüdas (v. 2), referencia a la artista norteamericana de color Joséphine Baker, que triunfaba

Odisea, $n^{\circ} 3,2003$ 
por los años treinta en espectáculos de music-hall; además son más viüdas, y la palabra viuda opera en un doble sentido, las veletas están más solas en lo alto de la torre y más negras, por el luto que impone la viudedad. El color de las veletas se desplaza a los vientos que son, por contigüidad metafórica, negros (v. 5) para finalmente presentarnos las veletas como bailarinas celestes de raza negra (danzarinas, si etiopes, celestes, v. 8).

El saber compartido sobre el mundo y las cosas (las veletas son negras, están en lo alto de las torres, son movidas constantemente por el viento, a veces, sin marcar una dirección fija) es lo que nos permite enfrentarnos con un texto construido a partir de lo que Trujillo llama «actividad lingüística no referencial» ${ }^{9}$, un texto en el que el saber interpretativo de sus posibles destinatarios debe contar con que están activas en él - como ha señalado Coseriu para el lenguaje literario ${ }^{10}$ — todas las posibilidades lingüísticas, sin restricciones, incluida la de transformar en objeto poético y tratar poéticamente - todo Perito en lunas es recreación del estilo gongorino - lo que habitualmente queda al margen del ámbito literario.

En otro tipo de textos, de carácter infantil y festivo, es muy frecuente que el hablante tenga que aplicar una interpretación tolerante para anular la incongruencia aparente ${ }^{11}$ y no sólo eso, sino que el hablante ya está predispuesto a aceptar lo incongruente -en muchos casos, sin intentar ni siquiera una explicación razonable — porque percibe en ellos un juego del que se hace cómplice. En la canción infantil que sigue:

Que llueva, que llueva,

la virgen de la cueva,

los pajarillos cantan,

las nubes se levantan,

quesí,

${ }_{9}^{9}$ Dice el lingüista canario :

Es referencial el uso que tiene por objeto el representar lo más fielmente posible cosas, acontecimientos o, incluso, palabras; es no-referencial toda actividad lingǘstica que no consista en otra cosa que en el simple juego del lenguaje, sin proponerse decir qué es tal texto, cómo es o qué «quiere decir» (R. Trujillo 2002, 151).

${ }^{10}$ Así lo señala al afirmar:

Wenn das so ist, dann kann die dichterische Sprache nicht eine Modalität des Sprachgebrauchs unter anderen sein, dann kann sie nicht mit anderen Modalitäten wie der Altgssprache oder der wisswnschaftlichen Sprache koordiniert werden. Sie mub dann vielmehr als Sprache schlechthin angesehen werden, denn nur in ihr findet man die volle Entfaltung aller sprachlichen Möglichkeiten. (Coseriu 1994, 147).

11 En relación con esto Coseriu $(1988,141-147)$ se refiere a tres tipos de anulación de la incongruencia en el discurso: la anulación metafórica, en la que hay una transposición del significado codificado, o bien se atribuyen a las cosas designadas valores simbólicos nuevos; la anulación metalingüistica, en que lo incongruente es presentado como una realidad (Pedro es un profesor que no es un profesor, el ejemplo es mío) y la anulación extravagante, conectada con el «uso no referencial del lenguaje» de Trujillo, por la cual se tolera la incongruencia porque se la siente como intencional, es decir, se percibe el uso del lenguaje como juego o creación. Sin embargo, y aunque estoy de acuerdo grosso modo con los tres tipos de anulación de la incongruencia coserianos en los que se sustenta el principio de la interpretación tolerante, creo que la percepción de la incongruencia como intencional —aunque no como juego o creación- está presente en los tres tipos de anulaciones, pues si no entendemos la incongruencia como un procedimiento de expresión de un contenido congruente en los tres casos, no hay posibilidad efectiva de interpretación de este tipo de mensajes.

Odisea, $\mathrm{n}^{\circ} 3,2003$ 


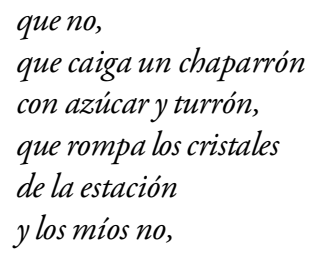

no rechazamos el texto como tal, aunque encontremos en él incongruencias palpables de acuerdo con nuestro conocimiento del mundo y de las cosas (todos sabemos que los chaparrones son de agua, no de azúcar y turrón) y tampoco intentamos explicárnoslas de forma razonable, sino que, extremando el principio de la tolerancia interpretativa, simplemente aceptamos el texto como se nos presenta, es decir, lo toleramos, renunciando incluso a parte de su interpretación.

\section{COHERENCIA, CONGRUENCIA E INTERPRETACIÓN TOLERANTE}

El principio de la congruencia coseriano se muestra, pues, especialmente interesante no sólo para la construcción textual sino, precisamente para indagar sobre los mecanismos que nos permiten interpretar textos, incluso aparentemente incongruentes. La congruencia es un principio general que se sitúa, como he apuntado más arriba, en el plano del hablar en general; es, por tanto, un principio que corresponde a las normas universales del hablar y que se manifiesta en una serie de exigencias o principios más específicos en que se va concretando (Coseriu 1981, 14). A. Vilarnovo (1991, 129-134) se ha ocupado de enumerar los principios específicos que, según Coseriu, permiten cumplir la exigencia de la congruencia y que ya han sido citados en este trabajo: un texto congruente ha de ajustarse a cumplir las exigencias de

a) Claridad,

por la cual se debe evitar la ambigüedad y tender a la precisión en lo que decimos (un enunciado como He visto a Juan mientras conducía ${ }^{12}$ infringe esta exigencia ya que no queda claro quién conducía).

b) Coherencia,

que obliga a que los mensajes producidos deban mantener una unidad, especialmente de sentido.

c) No contradicción,

que consiste en no decir cosas lógicamente incompatibles, aunque, como ya hemos visto, el principio de la tolerancia interpretativa permite anular la incongruencia de determinados textos que violan intencionadamente la exigencia de la no contrariedad lógica ${ }^{13}$

\footnotetext{
12 Ejemplo tomado de Vilarnovo (1991, 131).

13 Pensemos en textos poéticos de corrientes literarias muy concretas, como, por ejemplo, la poesía de vanguardia de distintas épocas. Difícilmente se ajusta a la exigencia de no contradicción el siguiente fragmento del poema Ocupado de Juan Larrea, incluido en el volumen titulado Versión celeste (Madrid: Cátedra), que básicamente recoge poemas aparecidos entre 1926 y 1932:

Ampáreme un autobús a motor de golondrinas entre esta bruma rellena de miga de violín
}

Odisea, $n^{\circ} 3,2003$ 


\section{d) No tautología,}

principio relacionado con otros -exigencia de no-repetición, de no decir lo obvioque propone Vilarnovo $(1991,131)$ para completar esta lista que ofrece Coseriu, aunque sin pretensiones de exhaustividad. La exigencia de la no tautología supone avanzar en lo que decimos y garantiza que los textos así producidos mantienen un grado adecuado de informatividad. Sería, en consecuencia, incongruente decir que una alcachofa es una alcachofa, texto con un grado 0 de informatividad. O, aunque no se trate de una tautología idiomática ( $A$ es $A$ ), también quedarían valorados como incongruentes los enunciados que podríamos denominar de razonamiento tautológico, como el siguiente ejemplo, correspondiente a la respuesta a una pregunta de examen, de nivel universitario, con el título «Las relaciones de hiponimia / hiperonimia y su papel en la enseñanza del vocabulario»:

Las relaciones hiponimia / hiperonimia se basan en el léxico; en relaciones semánticas, que son relaciones de palabras, que forman grupos específicos, en este caso uno de ellos es la relación de hiponimia / hiperonimia, que establece una gran relación semántica.

El trabajo de Vilarnovo se ocupa, pues, de la congruencia coseriana en relación con el principio de la coherencia textual. En efecto, para Coseriu, la coherencia, una de las dos propiedades fundamentales sobre las que se sustenta cualquier texto, es una de las manifestaciones de la congruencia. Lo interesante del planteamiento coseriano, y así lo señala Vilarnovo $(1991,129)$ es que permite un acercamiento a la coherencia desde una nueva perspectiva más abarcadora, que ayudaría a poner un cierto orden dentro de las posibilidades actuales de acercamiento a este fenómeno textual, que, sin contradicción y siguiendo el modelo coseriano, podríamos situar, según la forma de manifestarse, en los tres niveles del lenguaje ${ }^{14}$. Esta relación entre coherencia y congruencia ha sido también puesta de relieve por M. Casado Velarde $(1993,17)$ al hablar de las propiedades fundamentales que todo texto debe satisfacer: la coherencia y la cohesión. Para Casado Velarde

Por coherencia se entiende la conexión de las partes en un todo. Esta propiedad implica, pues, la unidad. Para algunos autores, como Coseriu, la coherencia representa un

\footnotetext{
y aún más cautelosa que un prejuicio de casta

ahora que el corazón del turismo palpita

suavemente escondido

y el universo se llena de miradas

$y$ de gorras a cuadros.
}

14 Esto significaría que la coherencia o unidad de los textos se consigue aplicando las normas del saber universal, pero también mediante procedimientos que tienen que ver con el saber idiomático y con el saber expresivo. Por ello no es de extrañar que en el momento actual nos encontremos en la bibliografía sobre la coherencia textual con una aparente disparidad de posturas en torno a este fenómeno (coherencia como dependiente de la cohesión de un texto, coherencia como cumplimiento del principio de la no contrariedad lógica, coherencia como el avance adecuado de la información de un texto o progresión temática y coherencia como algo externo al texto, por tanto, dependiente en gran medida del receptor), posturas que a veces parecen excluirse unas a otras, llegando incluso a alternar en distintas etapas cronológicas de un mismo autor (como le sucede a M. Charolles 1978 y 1994) cuando en realidad la aparente oposición entre los diferentes conceptos de coherencia desaparece si tenemos en cuenta la interacción entre los tres planos del lenguaje.

Odisea, $n^{\circ} 3,2003$ 
caso particular de lo que denomina congruencia o conformidad de la actividad lingüística con las normas universales del hablar. Estas normas universales del hablar constituyen el denominado saber elocucional, integrado por el conocimiento del mundo y de las cosas, los principios generales del pensar humano, la exigencia de claridad y de no repetición, el no decir lo obvio, lo imposible o extravagante, etc. Y, entre estos principios, se encuentra la coherencia.

Y como es frecuente en la bibliografía sobre el texto, Casado Velarde (1993) dedica el resto del trabajo objeto de la cita, a la presentación de los procedimientos de cohesión textual. Un somero vistazo a los estudios existentes sobre el discurso nos permite comprobar cómo la propiedad que ha suscitado más interés es, con mucha distancia, la cohesión ${ }^{15}$. A ello contribuye, probablemente, que los procedimientos que conectan las distintas partes de los textos entre sí son formalmente aislables, frente a la coherencia, que queda instalada en la vaguedad de la unidad de sentido. La contraposición entre la coherencia y la cohesión ha traído como consecuencia la equiparación de dos fenómenos que, teniendo en cuenta los tres niveles del lenguaje en que puede desarrollarse la actividad lingüística, no parecen equiparables. La coherencia pertenece, siguiendo a Coseriu, al plano lingüístico general, que está en conexión con la actividad humana del hablar en general. Desde esta perspectiva la coherencia pertenecería a los principios universales del hablar. Deberíamos entonces plantearnos las diferencias entre coherencia y cohesión considerándolas fenómenos de distinta naturaleza; la coherencia estaría en relación con los principios generales que gobiernan la construcción de los textos (Charolles 1988, 55), expresamente con el principio de la congruencia, del que derivarían los demás y que, según se trate de uno u otro tipo de textos y / o de determinadas situaciones de comunicación, está unido a los conceptos de adecuación, interpretación y -aunque con reservas - de corrección. No debemos olvidar que los procedimientos que permiten construir textos congruentes no tienen por qué ser procedimientos del mismo tipo ni solamente procedimientos lingüísticos aunque, en definitiva, su puesta en práctica tenga repercusiones lingüísticas. Así, la evaluación de la coherencia de un texto admite un juicio que lo sitúa dentro de una escala como texto más o menos coherente o, lo que es lo mismo, la coherencia es un fenómeno que se puede manifestar de forma gradual en los textos, ya que afecta globalmente a los mismos a través de los tres planos lingüísticos en que puede manifestarse. Y esto no puede aplicarse de la misma forma cuando nos referimos a la cohesión, que no se presta con facilidad y por decirlo de alguna manera, a ser medida cualitativamente, porque su análisis implica el uso, adecuado o no, de determinadas marcas. Considerar la coherencia y la cohesión como fenómenos de la misma naturaleza ha llevado a que buena parte de los estudios centrados en la coherencia constituyan una especie de refrendo de su naturaleza lingüística en que se intenta bien establecer las huellas lingüísticas que deja la coherencia en los textos (CarterThomas 2000), bien las condiciones para que se dé la coherencia textual (Comte 1988, Reinhardt 1980 y Giora 1985). Pero la coherencia es un fenómeno que afecta a todos los niveles del lenguaje, no sólo al de la lengua particular; por eso, ante la imposibilidad de un estudio

\footnotetext{
15 Podemos comprobar esto consultando la extensa bibliografía que recoge Luis Cortés (1995a, 63-82 y 1995b, 75-94) sobre un aspecto parcial que afecta a la cohesión textual: el empleo de marcadores del discurso. La nómina de estudios sobre marcadores no ha dejado de aumentar desde 1995, fecha de publicación de la bibliografía de L. Cortés.
}

Odisea, $\mathrm{n}^{\circ} 3,2003$ 
estrictamente lingüístico de esta propiedad textual, hay también otro tipo de trabajos que prefieren situar la coherencia dentro del ámbito de la pragmática como un requisito de naturaleza fundamentalmente extralingüística (Charolles 1994). Entre algunos investigadores, hay cierta falta de confianza en la posibilidad de un análisis textual de la coherencia debida, probablemente, al intento de aplicación de los mismos métodos que en el estudio de la cohesión y al intento de buscar en los textos, como se hace con la cohesión, marcas palpables de la coherencia, sin considerar, como ya he señalado más arriba, que la coherencia es un fenómeno que se manifiesta de forma global en los textos y que afecta, por esta razón, a todos los niveles textuales ${ }^{16}$. La dificultad para aplicar a la coherencia los mismos criterios de análisis que a la cohesión ha llevado a distintas posturas metodológicas en el acercamiento a la coherencia y en alguna de esas posturas la coherencia acaba apareciendo como un fenómeno, no sólo estrechamente relacionado con la cohesión - cosa que no podemos negar-, sino dependiente de la cohesión, aun existiendo textos coherentes sin elementos cohesivos explícitos y textos incoherentes - hemos visto una muestra en la nota 13 - perfectamente cohesionados. Uno de los intentos más radicales para explicar la coherencia a través de la cohesión es el de R. Hasan (1984), para la cual, no sólo la cohesión de los textos es un requisito fundamental que explica la coherencia textual, sino que el nivel de coherencia de un texto puede medirse utilizando el índice de armonía cohesiva, que consiste en hallar el porcentaje de palabras relacionadas semánticamente y / o gramaticalmente entre sí. El método de Hasan es estrictamente cuantitativo, pues no tiene en cuenta otros factores que pueden influir en la coherencia, como son el tipo de texto o la situación comunicativa, por lo que ha sido cuestionado por otros autores como M. Díaz Prados $(2001,1121)$, que intentado medir la coherencia de textos concretos calculando el índice de armonía cohesiva de Hasan, acaba por concluir que así sólo se consigue medir la cohesión, pero no la coherencia. En efecto, la coherencia textual, más que con el empleo adecuado - que la favorece- de los elementos cohesivos tiene que ver con la manera de desarrollar la información contenida en un texto ${ }^{17}$, por eso hay que tener también en cuenta otros factores a la hora de relacionar ambas propiedades textuales, factores que derivan de la situación de la coherencia dentro de la congruencia coseriana, como una manifestación de los principios universales que regulan el hablar en general. Ello es lo que hace que, para considerar un texto coherente sea requisito fundamental la no contrariedad lógica ${ }^{18}$ entre sus partes; tanto es así que siguiendo la visión coseriana de la congruencia la coherencia sería un caso particular de la congruencia, y la cohesión, a su vez, podría interpretarse como un caso particular de la coherencia (Vilarnovo 1991, 134). No podemos, pues, hacer depender la coherencia de la cohesión porque se sitúan en niveles diferentes del lenguaje: la coheren-

\footnotetext{
${ }^{16}$ Así lo señala P. Sgall $(1983,135)$ cuando afima que

The question of coherence of a text or a discourse concern all the levels of the language system, from phonetics and phonemics through morphemics and surface syntax up (or down) to meaning. Phenomena belonging to the most different levels characterize a text as more or less coherent.

${ }^{17}$ De hecho, donde se han obtenido los mayores avances en el estudio de la coherencia textual ha sido en el terreno de la progresión temática o, dicho de otro modo, en la indagación sobre «los mecanismos merced a los cuales se transmite la información desde la concepción del texto como resultado del equilibrio entre la progresión y la redundancia informativa.»(J. M. Bustos Gisbert 1996, 30)

18 Para M. E. Comte el concepto de coherencia puede definirse negativamente como la no contrariedad que todo texto debe poseer para tener unidad de sentido (1988, 29-30).
}

Odisea, $n^{\circ} 3,2003$ 
cia en el plano del saber universal y la cohesión o, mejor dicho, los procedimientos cohesivos, en el plano del saber idiomático y expresivo. Además, como ya se ha señalado más arriba, la relación cohesión - coherencia no es simétrica, lo que nos lleva a valorar como incongruentes textos perfectamente cohesionados y con unidad de sentido, es decir, coherentes. En el siguiente ejemplo de Julio Cortázar:

\section{INSTRUCCIONES PARA LLORAR}

Dejando de lado los motivos, atengámonos a la manera correcta de llorar, entendiendo por esto un llanto que no ingrese en el escándalo, ni que insulte a la sonrisa con su paralela y torpe semejanza. El llanto medio u ordinario consiste en una contracción general del rostro y un sonido espasmódico acompañado de lágrimas y mocos, estos últimos al final, pues el llanto se acaba en el momento en que uno se suena enérgicamente.

Para llorar, dirija la imaginación hacia usted mismo, y si esto le resulta imposible por haber contraido el hábito de creer en el mundo exterior, piense en un pato cubierto de hormigas o en esos golfos del estrecho de Magallanes en los que no entra nadie, nunca.

Llegado el llanto, se tapará con decoro el rostro usando ambas manos con la palma hacia dentro. Los niños llorarán con la palma del saco contra la cara, y de preferencia en un rincón del cuarto. Duración media del llanto, tres minutos.

(Cortázar, J. 1970. Historias de cronopiosy de famas. Buenos Aires / Barcelona: Editorial Sudamericana / EDHASA, 1979, p. 11),

es evidente que se viola la máxima de no decir lo obvio. No resulta fácilmente explicable la construcción de un texto tan detallado y tan minucioso para dar instrucciones sobre la correcta realización de un acto, el de llorar, que todos llevamos a la práctica de manera intuitiva, natural y no programada. Sin embargo, el texto presenta una alto índice de armonía cohesiva y una gran unidad de sentido. El control temático del texto también es el adecuado: los tres párrafos que lo componen lo hacen progresar temáticamente a través del patrón discursivo del tema constante (el tema el llanto se repite en las distintas oraciones que conforman cada párrafo). En el primer párrafo Cortázar sienta el marco discursivo del texto con una definición de lo que se considera llanto medio u ordinario, en el segundo párrafo se nos dan instrucciones para conseguir llorar y en el tercero se nos dice cómo debe ser el llanto (características y duración). Y, sin embargo, el texto no es congruente. Pero el hecho de que el texto esté construido tan cuidadosamente, de acuerdo con las reglas del saber idiomático y del expresivo, es una manera de activar el principio de la interpretación tolerante de Coseriu, que nos permite enfrentarnos con textos aparentemente incongruentes. Nadie se toma tantas molestias al elaborar lo que nos dice para nada, por lo que los hablantes tendemos a aceptar como válidos textos que no son congruentes si poseen una gran armonía cohesiva. Incluso, como ya hemos visto, en determinados tipos de discurso (es muy común esto en el mundo de la literatura infantil y festiva) una fuerte armonía cohesiva unida a desarrollos temáticos que en algún o en muchos puntos se apartan de las normas que regulan la congruencia, se convierte en un procedimiento formal en que el envoltorio del texto fuerza, no ya una interpretación del mismo, sino la asunción inmediata de sus presu-

Odisea, $n^{\circ} 3,2003$ 
puestos. En el texto de Cortázar, si sabemos que pertenece a una obra literaria, la alteración de los principios de la congruencia contribuye, precisamente, a dotar de sentido al texto, pues nos indica que se trata de una creación, de un juego humorístico. Pero si no sabemos que este texto está inserto en una obra literaria de determinado tipo, si nos llega como un texto aislado, también mediante el principio de la interpretación tolerante intentaríamos buscarle un sentido congruente, por ejemplo, acudiendo a una hipotética situación en que podamos emitir este texto con un sentido (podría ser en una escuela de actores, practicando la interpretación de emociones).

Desde la perspectiva anterior, el principio de la interpretación tolerante de Coseriu, se relaciona con una visión de la coherencia que la hace depender del receptor. A. Vilarnovo (1990) distingue dos tipos de coherencia textual: coherencia interna, es decir, intratextual y coherencia externa, por la cual

La coherencia no estaría tanto en el texto como en el sujeto intérprete del texto; la coherencia sería más bien una propiedad atribuida por el intérprete y no un elemento externo al texto. (p. 233)

En efecto, como dice Hobbs $(1983,29)$ «Discourse tends to be coherent», por eso los destinatarios de un texto tienden a buscarle una interpretación, tienden a considerar pertinente y coherente la información que se contiene en él. Por esta razón, en esta visión de la coherencia como externa al texto es muy importante el contexto así como también los conocimientos lingüísticos y culturales compartidos por los participantes en la comunicación. Así considerada, la coherencia no es para algunos autores (Charolles 1994) sino una forma particular del principio de la pertinencia / relevancia elaborado por D. Sperber y D. Wilson (1986), por el cual las personas buscamos en la relación entre lo dicho y el contexto la pertinencia mayor, es decir, el efecto cognitivo mayor - la mayor información - en relación con el esfuerzo de tratamiento menor. Por eso también los hablantes esperamos de los textos congruencia y coherencia o unidad de sentido, pues son necesarias para su interpretación. Resulta más sencilla la interpretación de un texto mal cohesionado o mal construido con arreglo al saber idiomático, a la lengua particular, siempre que esté bien construido con arreglo a las normas que rigen el hablar en general, es decir, siempre que esté dotado de congruencia. Así, aunque reconozcamos que no son textos correctos, muchas veces somos capaces de alcanzar el sentido de enunciados imperfectos idiomáticamente, como los de un niño que está adquiriendo su lengua o un hablante extranjero. De hecho, es muy frecuente que en la literatura aparezcan textos con errores idiomáticos prototípicos para caracterizar a un hablante como integrante de un grupo: en los niños es muy común el recurso al ceceo infantil indiscriminado y en hablantes extranjeros se recurre a la extensión de algún fallo en relación con nuestra lengua, como comprobamos en el siguiente ejemplo (un interrogatorio), en que un hablante ruso ${ }^{19}$ viene caracterizado por la ausencia de artículos:

-De acuerdo-aceptó- ¿Qué necesitas saber?

-Por ejemplo, cuándo fue la última vez que la vio o habló con ella.

- Mismo día que desapareció. Estuve con ella hasta final de tarde. Luego yo tenía cosas que hacer y sali. Ella fue a trabajo. Me llamó desde alli hacia doce noche, más o menos. Y ésa fue última vez que hablé.

- ¿Recuerda lo que le dijo ella en esa conversación?

\footnotetext{
19 Señalo en cursiva la parte de diálogo correspondiente al hablante extranjero.
} 
-Que habia salido buen negocio. Unos clientes de Madrid. Que tenía que marchar treso cuatro dias. Eso fue todo.

(Silva, L. 2000. El alquimista impaciente. Barcelona, Ediciones Destino, p. 128).

El ejemplo anterior afecta más al saber hablar que al saber interpretar, aunque hay que reconocer que la comprensión del sentido de un texto como el de L. Silva está supeditada a un mínimo de corrección idiomática. Pero cuando se activa la interpretación tolerante de la que habla Coseriu, nos movemos más bien en el terreno del saber interpretar, aunque no exclusivamente. La interpretación tolerante está íntimamente relacionada, si es que no determinada, por la posibilidad de anular la incongruencia de ciertos enunciados en circunstancias concretas. Esa anulación se basa en la posibilidad que tienen los hablantes de suspender eventualmente los principios que regulan la congruencia cuando hay causa suficiente o una intención específica- para ello. Coseriu se ha referido en diversos lugares a la anulación de la incongruencia (1978, 39-41), tanto por las lenguas particulares (1988, 136-140) como en el discurso (1988, 141-147). Es precisamente en el discurso, donde tiene lugar el grueso de las anulaciones de los textos aparentemente incongruentes y donde el hablante tiene que colaborar con una interpretación tolerante para anular la incongruencia. Los tres tipos posibles de anulaciones discursivas propuestos por Coseriu («hay por lo menos tres tipos de anulaciones en el discurso» Coseriu 1988, 141), anulación metafórica, anulación metalingüística y anulación extravagante, exigen un grado diferente de colaboración por parte del destinatario de un texto: en el primer caso, las palabras adquieren significados insospechados, pero dotados de una congruencia simbólica que hay que descubrir (cuando Gerardo Diego identifica un ciprés con un enhiesto surtidor de sombra y sueño, se ha producido una anulación metafórica); en el segundo caso, presentamos las cosas como son, pero el modo de expresarnos es incongruente (si alguien me dice que cuando tiene exámenes, Juan no es Juan está presentándonos un contenido no contradictorio -Juan parece otra persona cuando tiene exámenes - a través de una forma lingüística contradictoria); en el tercer caso, asistimos a «la afirmación intencional de lo absurdo e incongruente» (Coseriu 1988, 145), lo que se produce cuando usamos el lenguaje como juego o creación; y es en esta tercera anulación donde puede darse la máxima tolerancia interpretativa.

Una interpretación tolerante no significa que la coherencia sea un propiedad que dependa exclusivamente de factores externos al texto y, por tanto, difícilmente aprehensibles por su ilimitada variedad, significa que existen procedimientos para crear textos aparentemente incongruentes y procedimientos para anular esas incongruencias. Y esos procedimientos operan sin contradicción en los tres planos del lenguaje coserianos. Por último, y para cerrar este trabajo, quiero insistir en que no poner en relación los tres niveles del lenguaje cuando se aborda el estudio de las propiedades textuales lleva a la incomprensión de las diferencias entre ellas y a la exclusión de fenómenos que, aunque extralingüísticos, también tienen repercusiones textuales. Por eso la visión coseriana de la congruencia integra puntos de vista que normalmente se consideran separados y abre una nueva perspectiva, más abarcadora y más explicativa, en el estudio de las propiedades de los textos.

Odisea, $n^{\circ} 3,2003$ 


\section{BIBLIOGRAFÍA}

Bustos Gisbert, J. M. 1996. La construcción de textos en español. Salamanca: Ediciones Universidad de Salamanca (Manuales Universitarios 62).

Carter-Thomas, Sh. 2000. La cohérence textuelle. Pour une nouvelle pédagogie de l'écrit. Paris / Montréal: L'Harmattan.

CASAdo Velarde, M. 1993. Introducción a la gramática del texto en español. Madrid: Arco/Libros (Cuadernos de lengua española).

Charolles, M. 1978. «Introduction aux problèmes de la cohérence des textes». Langue Française XXX: 7-41.

—1988. «Les études sur la cohérence, la cohésion et la connexité textuelles depuis la fin des années 1960». Modèles Linguistiques 10/2: 45-66.

— 1994. «Cohésion, cohérence et pertinence du discours». Travaux de Linguistique et Philologie 29: 125-151.

Cомте, M.-E. 1988. Condizioni di coerenza. Ricerche di linguistica testuale. Firenze: La Nuova Italia Editrice.

Cortés Rodríguez, L. 1995a. «Bibliografía: marcadores del discurso (I)». Español Actual 63: 63-82.

—1995b. «Bibliografía: marcadores del discurso (y II)». Español Actual 64: 75-94.

Coseriu, E. 1962a. «Determinación y entorno. Dos problemas de una lingüística del hablar». Teoría del lenguaje y lingüistica general. Madrid: Gredos (Biblioteca Románica Hispánica 61). 282-323.

_ 1962b. «Sistema, norma y habla». Teoría del lenguaje y lingüística general. Madrid: Gredos (Biblioteca Románica Hispánica 61): 11-113.

1981 (1973). Lecciones de lingüística general. Madrid: Gredos (Biblioteca Románica Hispánica 51).

1977. El hombre y su lenguaje. Madrid: Gredos (Biblioteca Románica Hispánica 272).

-1987 (1978). «Lógica del lenguaje y lógica de la gramática». Gramática, semántica, universales. Estudios de lingüística funcional. Madrid: Gredos (Biblioteca Románica Hispánica 280), 2a . ed. revisada: 15-49.

-1981. «La socio- y la etnolingüística. Sus fundamentos y sus tareas». Anuario de Letras 19: 5-30.

1988. Competencia lingüística. Elementos de la teoría del hablar. trad. Francisco Meno Blanco. Madrid: Gredos (Biblioteca Románica Hispánica 377), 1992.

-1994. Textlinguistik. Eine Einführung. Tubinga: Francke Verlag.

_1997. «Tesis acerca del «significado»». Lexis XXI/2: 83-86. 
DíAz Prados, M. 2001. «Acercamiento al concepto de coherencia». Lengua, discurso, texto (I Simposio Internacional de Análisis del Discurso). Ed. J. J. de Bustos Tovar et al. Madrid: Visor, vol. 1. 1111-1123.

García Hernández, B. y J. Polo 1999. Solemne acto académico con motivo de la investidura como Doctor "Honoris Causa» de los Profesores Carlos Castilla del Pino, Eugenio Coseriu y José Elguero Bertolini. Universidad Autónoma de Madrid: Secretería General. 25-33.

Giora, R. 1985. «Notes toward a theory of text coherence». Poetics Today 6/4: 699-715.

HasAn, R. 1984. «Coherence and Cohesive Harmony». Understanding Reading Comprehension: Cognition, Language and the Structure of Prose. J. FLood, ed. Delaware: International Reading Association. 181-219.

HobBs, J. R. 1983. «Why is discourse coherent?». Coherence in Natural-Language Texts. F. Neubauer, ed. Hamburg: Helmut Buske Verlag. 29-70.

LóPez García, Á. 2000. «Teoría gramatical». Introducción a la lingüística española. M. Alvar, ed. Barcelona: Editorial Ariel. 7-22.

Moreno CABrera, J. C. 2002. «El motor de la economía lingüística: de la ley del mínimo esfuerzo al principio de la automatización retroactiva». Revista Española de Lingüistica 32/1: 1-32.

Narbona, A. 1989. «Sintaxis coloquial: problemas y métodos». Sintaxis española: nuevos y viejos enfoques. Barcelona: Editorial Ariel. 150-169.

Polo, J. 2000. «Cómo nace una bibliografía gramatical». Introducción a la lingüística española. M. Alvar, ed. Barcelona: Editorial Ariel. 581-622.

Reinhardt, T. 1980. «Conditions for text coherence». Poetics Today I/4: 161-180.

Schmidt, S. L. 1980. Fundamentos de la ciencia empírica de la literatura. Trad. Francisco Chico Rico. Madrid: Taurus, 1990.

SGALl, P. 1983. «On one aspect of textual coherence». Coherence in Natural-Language Texts. F. Neubauer, ed. Hamburg: Helmut Buske Verlag. 135-143.

Trujlllo, R. 2002. «La forma en la lengua y en la poesía». Lingüística española actual XXIV/2: 145-163.

Vilarnovo, A. 1990. «Coherencia textual: ¿coherencia interna o coherencia externa?». Estudios de Lingüística de la Universidad de Alicante 6: 229-239.

-1991. «Teorías explicativas de la coherencia textual». Revista Española de Lingüística 21/1: 125-144. 